\title{
Knowledge, Attitudes and Concussion Information Sources Among First Nations in Ontario
}

\author{
Cindy Hunt, Alicja Michalak, Elaine Johnston, Chrissy Lefkimmiatis, \\ Leila Macumber, Tony Jocko, Donna Ouchterlony
}

\begin{abstract}
Objective: Hockey is a popular sport played by many First Nation youth. Concussion frequently goes unrecognized and unreported in youth hockey. Unintentional injuries among Indigenous youth occur at rates three to four times the national Canadian average. The study sought to examine knowledge, attitudes and sources of concussion information among First Nations people attending a provincial hockey tournament. Methods: A cross-sectional survey was undertaken. The survey by Mzazik et al. were modified to use in this study. Participants included youth (6-18 years) hockey players $(n=75)$, parents $(n=248)$ and coaches $(n=68)$. The main outcome measure was total knowledge index (TKI) which consisted of the sum of correct responses to 15 multiple choice questions. Additional data gathered included demographics, concussion history, attitudes toward concussion and sources of information. Descriptive statistics included proportion comparisons. Variables were tested using $\chi^{2}$ and analysis of variance. Results: Overall TKI scores (out of a total of 15) were low; players $(5.9 \pm 2.8)$, parents $(7.5 \pm 2.6)$ and coaches $(7.9 \pm 2.6)$. Participants with higher knowledge scores reported more appreciation of the seriousness of concussion. Sources of information about concussion differed by study group, suggesting the need for multiple knowledge translation strategies to reach youth, parents and coaches. Conclusions: Future initiatives are urgently needed to improve education and prevention of concussion in First Nations youth hockey. Collaborating and engaging with communities can help to ensure an Indigenous lens for culturally safe interventions.
\end{abstract}

RÉSUMÉ: Connaissances, attitudes et sources d'information au sujet des commotions cérébrales parmi les Premières Nations d'Ontario. Objectif: Le hockey est un sport populaire que pratiquent de nombreux jeunes issus des Premières Nations. On le sait, les commotions cérébrales passent souvent inaperçues et ne sont pas signalées chez les jeunes hockeyeurs. Chez ceux issus des Premières Nations, des blessures non-intentionnelles surviennent trois à quatre fois plus souvent que la moyenne canadienne. Cette étude a donc pour but de se pencher sur les connaissances, les attitudes et les sources d'information au sujet des commotions cérébrales que possèdent les membres de Premières Nations ayant assisté à un tournoi de hockey provincial. Méthodes: Nous avons mené une enquête ponctuelle. L'enquête déjà menée par Mzazik et al. a été modifiée afin que nous puissions l'utiliser dans le cadre de cette étude. L'ensemble des participants incluait des jeunes âgés de 6 à 18 ans, des hockeyeurs $(\mathrm{n}=75)$, des parents $(\mathrm{n}=248)$ ainsi que des entraîneurs $(\mathrm{n}=68)$. La principale mesure de nos résultats a été un indice total de connaissances (total knowledge index ou TKI), lequel a consisté en la somme de bonnes réponses données à 15 questions à choix multiples. Des données additionnelles ont également été collectées en ce qui concerne le profil démographique des participants, leurs antécédents en matière de commotion cérébrale, leurs attitudes à l'égard de ce type de traumatisme et leurs sources d'information. Nos statistiques descriptives ont notamment inclus des comparaisons de type proportionnel. Nos variables ont été testées au moyen du $\chi 2$; de plus, nous avons également effectué une analyse de variance. Résultats: Dans l'ensemble, les scores obtenus au TKI (sur un total de 15) se sont avérés bas : hockeyeurs $(5,9 \pm 2,8)$, parents $(7,5 \pm 2,6)$ et entraîneurs $(7,9 \pm 2,6)$. Les participants ayant obtenu, en lien avec leurs connaissances, des scores plus élevés ont davantage souligné le caractère sérieux des commotions cérébrales. Les sources d'information au sujet des commotions cérébrales étaient différentes selon les sous-groupes à l'étude, ce qui suggère la nécessité de compter sur des stratégies multiples de transmission de connaissances pour rejoindre les jeunes, leurs parents et leurs entraîneurs. Conclusions: Il est urgent, dans l'avenir, de compter sur des initiatives visant à améliorer l'éducation et la prévention des commotions cérébrales chez les jeunes hockeyeurs issus des Premières Nations. Des communautés prêtes à collaborer et à s'engager pourraient à cet égard assurer une «perspective autochtone » dans le cadre d'interventions appropriées sur le plan culturel.

Keywords: Brain injury—traumatic, Brain injury—pediatric, Education, Head trauma

doi:10.1017/cjn.2017.299

Can J Neurol Sci. 2018; 45: 283-289

\section{INTRODUCTION}

Hockey is a popular sport played by First Nations (includes status and non-status Indians) youth in Ontario. Reports have shown that at least one in ten youth (6-18 years) will suffer a concussion while playing ice hockey in Canada. ${ }^{1}$ Young athletes
From the Head Injury Clinic, Trauma \& Neurosurgery Program, St. Michael's Hospital, Toronto, ON, Canada (CH, AM, CL, DO); Serpent River First Nation, Cutler, ON, Canada (EJ); Kenabutch Health Centre, Serpent River First Nation, Cutler, ON, Canada (LM); Union of Ontario Indians, North Bay, ON, Canada (TJ).

Received July 21, 2017. Final Revisions Submitted October 20, 2017. Date of AcCePTANCE November 20, 2017.

Correspondence to: Cindy Hunt, Head Injury Clinic, Trauma \& Neurosurgery Program, St. Michael's Hospital, 193 Yonge St., 3rd Floor, Toronto, ON, Canada M5B 1M8. Email: huntci@smh.ca 
are more susceptible to concussion due to larger head to body size ratio, weaker neck muscles and increased vulnerability of the developing brain. ${ }^{2}$ Differences in the physical size of young hockey players can also contribute to the risk of concussion. ${ }^{3}$ Even minor concussions in hockey are serious injuries for youth. ${ }^{4}$ They have the potential to lead to a second impact syndrome which can result in severe neurological deficits and even death. ${ }^{5}$ Youth take longer to recover from a concussion compared to adults. Furthermore, an estimated $21 \%-73 \%$ of young patients who experience a concussion may develop post-concussive syndrome. ${ }^{6-8}$ Post-concussive syndrome is defined as at least one symptom for at least 4 weeks and can result in a heterogeneous population of youth with chronic disability requiring costly and multidisciplinary intervention. ${ }^{8-12}$ Post-concussive syndrome can impact a youth's education, future employability and ability to integrate within their community. ${ }^{13}$ It can contribute to depression, substance abuse and suicide. ${ }^{14,15}$ Aspects of hockey culture can place an overemphasis on winning games. The lack of understanding and misperceptions about health risks associated with concussion have all been identified as reasons that concussions go unrecognized, unreported and unmanaged in youth hockey. ${ }^{16}$

Unintentional injuries among Indigenous (First Nations, Inuit and Metis) youth occur at rates three to four times the national Canadian average. ${ }^{17}$ Striking health inequities result from many factors, such as reduced access to medical and rehabilitation services, lack of sport safety equipment ${ }^{18}$ and lack of safety education. ${ }^{19}$ Only two articles ${ }^{20,21}$ were identified in a recent literature review of studies on traumatic brain injury in North American Indigenous populations. ${ }^{18}$ These early calls to action for Indigenous brain injury prevention have been unrequited. There is growing public health concern over the vulnerability of the developing brain to injury, ${ }^{8}$ the long-term consequences ${ }^{11,22}$ and high costs ${ }^{23}$ of sport-related concussion injuries. ${ }^{8,24}$

Concussions may occur subtly during hockey and are often difficult for even trained coaches to identify. ${ }^{25}$ At present, there is no single validated tool to diagnose a concussion or to determine when a player should return to play. ${ }^{25}$ Subjective symptom reporting is essential to identify and limit neurological trauma. ${ }^{26}$ Young athletes have been shown to underreport between $50 \%-75 \%$ of concussions. ${ }^{27}$ Evidence has demonstrated that improved knowledge of concussion among youth can lead to improved concussion symptom reporting. ${ }^{27}$ Parents also play an important role in the identification of concussion symptoms in youth and in managing their at home recovery. ${ }^{28,29}$ In cases where medical professionals are not available to manage concussion, coaches are often left in the position of managing both the concussed athlete and the game. ${ }^{30}$ Therefore, ensuring coaches have sound knowledge of concussion is also important. The objective of this study was to investigate knowledge, attitudes and sources of information about concussion among young recreational hockey players, parents and coaches participating in a 3-day provincial First Nations hockey tournament in Ontario.

\section{MeTHODS}

\section{Ethics, Study Design and Study Population}

This study was conducted in collaboration with First Nations partners which included Serpent River First Nations, Union of Ontario Indians and the Little Native Hockey League (LNHL).
Ethical approval was received from the Chief and Band Council of the Serpent River First Nations, the LNHL organization and the St. Michael's Hospital Institutional Review Ethics Board. The research study was conducted within the First Nations principles of ownership, controlled access and possession. ${ }^{31}$

Data collection was by the administration of a cross-sectional survey during the annual provincial hockey tournament. Participants were invited to sit at a table to complete the paper and pencil survey. All study participants had the opportunity to enter a draw for an i-PAD by submitting ballots separate from the questionnaire.

Approximately 80 First Nations youth hockey teams from across Ontario competed in the three day tournament with parents, relatives and community members in attendance. Study recruitment posters were placed on the hockey tournament web site in advance. A total of 391 participants completed the study questionnaire. Three participant groups were selected for comparisons, players $(n=75)$, coaches $(n=68)$ and parents $(n=248)$. Players were aged 6-18 years and competing in the tournament. Coaches included team managers, hockey officials and referees. The parent category included family members and other community members aged 19 years and older. If a parent was also a coach they were classified as "coach", as coaches usually receive first aid training.

\section{Survey Tool}

The survey instrument published by Mrazik et al. ${ }^{32}$ was selected with modifications undertaken. The number of questions from the published survey was reduced in order to provide a brief tool suitable for players, parents and coaches to complete within a 10-minute time frame. The study team decided that this time frame would be suitable to the study setting of a busy arena during a hockey tournament. The tool had four sections all with a multiple choice format. The first section consisted of five knowledge questions. Three of the five questions addressed recognition of concussion, return to play and frequency of concussion in young recreational hockey players (questions 2,7,9). ${ }^{32}$ The study team added two new questions regarding length of symptoms and return to school (see Appendix). The second section of the tool addressed symptom recognition. It consisted of a list of ten symptoms (eight concussion symptoms and two distractors (question 12). ${ }^{32}$ The third section of the survey had three attitude questions regarding seriousness, likelihood of and worry about a concussion in hockey (questions $8,10,11){ }^{32}$ Minor wording changes of the study instrument included changing, "If you were to play hockey how likely is a concussion" to "If you/ your child/a child you know were to play hockey how likely is it that you/your child/a child you know could get a concussion". The fourth section of the survey consisted of one question whereby participants selected their sources of concussion information from a list of eight possible sources. Data on demographics (gender and closest city to their residence) and history of concussion(s)(see appendix) were also collected.

\section{Outcome Measures}

The primary outcome measure was total knowledge index, scored out of 15 points. It was derived from the sum of correct responses to the knowledge questions (5) added to the symptom scores (total of ten points; eight for correct symptoms and two 
Table 1: Characteristics of participants by study group

\begin{tabular}{l|c|c|c|c|c}
\hline Group & $\boldsymbol{N}$ & $\begin{array}{c}\text { Female } \\
(\boldsymbol{n}[\%])\end{array}$ & $\begin{array}{c}\text { Age } \\
(\mathbf{m e a n} \pm \mathbf{S D})\end{array}$ & $\begin{array}{c}\text { Concussion } \\
\text { history }(\boldsymbol{n}[\%])\end{array}$ & $\begin{array}{c}\text { Region } \\
(\boldsymbol{n}[\%])\end{array}$ \\
\hline & & & & 0 & Toronto \\
\hline & & & & 1 & Sudbury \\
\hline & & & & 2 & Southwest \\
\hline Players & 75 & $46(61.3 \%)$ & $13.64 \pm 2.14$ & $58(77.3 \%)$ & $25(33.3 \%)$ \\
\hline & & & & $8(10.7 \%)$ & $18(24.0 \%)$ \\
\hline & & & & $4(5.3 \%)$ & $7(9.3 \%)$ \\
\hline & & & & $5(6.7 \%)$ & $25(33.3 \%)$ \\
\hline Coaches & 68 & $32(47.1 \%)$ & $40.34 \pm 10.1$ & $35(51.5 \%)$ & $24(35.3 \%)$ \\
\hline & & & & $14(20.6 \%)$ & $23(33.8 \%)$ \\
\hline & & & & $3(4.4 \%)$ & $4(5.9 \%)$ \\
\hline Parents & 248 & $199(80.2 \%)$ & $45.0 \pm 12.8$ & $184(74.2 \%)$ & $59(23.8 \%)$ \\
\hline & & & & $35(14.1 \%)$ & $64(25.8 \%)$ \\
\hline & & & & $15(6.0 \%)$ & $44(17.7 \%)$ \\
\hline & & & & $14(5.6 \%)$ & $81(32.7 \%)$ \\
\hline
\end{tabular}

points for the correct identification of distractors). In addition, a mean total knowledge score (MTKS) (used in Table 4) was also calculated and consisted of the sum of correct knowledge and correct symptoms only (excluding the distractors) resulting in a total possible score of 13. A higher score indicated greater understanding of the risk and significance of concussion.

\section{Analysis}

Descriptive statistics (frequency, proportions, means and standard deviations) were performed (see Table 1$) \cdot \chi^{2}$ tests were used for between group comparisons of individual items in the survey. Analysis of variance with post hoc analysis was used to compare general knowledge score, symptom knowledge score and total knowledge index by group. Percentages of players, parents and coaches using various sources of information about concussion were compared using a $Z$ test. All statistical analyses were performed using SPSS version 20.

\section{Results \\ Study Participants}

Study participants resided in Ontario with almost half from northern regions, one-third from the central Toronto region and fewer from the southwest region of Ontario. Females represented $80 \%$ of parents, $61 \%$ of players and $47 \%$ of coaches. Results showed a statistically significant differences in gender between players and parents $\left(\chi^{2}=16.786, p=0.001\right)$ and between coaches and parents $\left(\chi^{2}=27.595, p=0.001\right)$. Differences between players and coaches by gender was not significant $\left(\chi^{2}=1.217, p=0.270\right)$.

Among coaches $49 \%$ reported previous concussion(s), in contrast to $23 \%$ of the players and $26 \%$ of the parents. For those with previous concussions, three or more was reported by $24 \%$ of the coaches, $7 \%$ of players and $6 \%$ parents of parents. There was a significant difference in previous concussions between players and coaches $\left(\chi^{2}=9.199, p=0.002\right)$ and coaches and parents $\left(\chi^{2}=9.705, p=0.002\right)$. Findings between players and parents for previous concussion(s) was not statistically significant $\left(\chi^{2}=0.456, p=0.499\right)$.

\section{Knowledge}

Frequencies and percentages of correct knowledge questions, knowledge and symptoms scores, and total knowledge index are summarized in Table 2. Study participants demonstrated a good understanding of two of the five knowledge items, with recognition of concussion and return to school, receiving the greatest number of correct responses. The length of the duration of concussion symptoms was underestimated, with players having the fewest number of correct responses (players $9.3 \%$, parents $22.6 \%$, coaches $30.9 \%$ ). Prevalence of concussion in hockey was also misunderstood. Players again had the fewest number of correct responses (players $14.7 \%$, parents $26.6 \%$ and coaches $30.9 \%$ ). The question referring to when a hockey player should return to play had few correct responses (players $18.7 \%$, parents $19.4 \%$ and coaches $23.5 \%$ ). The mean knowledge scores were as follows; for players $1.9 / 5$, parents $2.2 / 5$ and coaches $2.5 / 5$. Differences in knowledge scores amongst the three groups were statistically

Table 2: Hockey scores, symptom scores and total knowledge index by study group

\begin{tabular}{|c|c|c|c|c|c|}
\hline Correct response & $N=75$ & $N=68$ & $N=248$ & $\chi^{2}$ & $p$-value \\
\hline & Players $(n[\%])$ & Coaches $(n[\%])$ & Parents $(n[\%])$ & & \\
\hline Grounds for a concussion & $55(73.3)$ & $51(75.0)$ & $155(62.5)$ & $\chi^{2}=5.568$ & 0.062 \\
\hline Length of symptoms* & $7(9.3)$ & $21(30.9)$ & $56(22.6)$ & $\chi^{2}=10.302$ & 0.006 \\
\hline Player return to play & $14(18.7)$ & $16(23.5)$ & $48(19.4)$ & $\chi^{2}=0.678$ & 0.713 \\
\hline Back to school & $56(74.7)$ & $58(85.3)$ & $213(85.9)$ & $\chi^{2}=5.462$ & 0.065 \\
\hline How often & $11(14.7)$ & $21(30.9)$ & $66(26.6)$ & $\chi^{2}=5.859$ & 0.053 \\
\hline Knowledge score $(/ 5$ mean $+\mathrm{SD}) *$ & $1.9 \pm 1.0$ & $2.5 \pm 1.0$ & $2.2 \pm 0.9$ & $F(2,388)=6.173$ & 0.002 \\
\hline Symptom score $(/ 10$ mean $+\mathrm{SD}) * *$ & $4.0 \pm 2.3$ & $5.5 \pm 2.5$ & $5.3 \pm 2.4$ & $F(2,388)=10.167$ & 0.001 \\
\hline Total knowledge index $(/ 15$ mean $+\mathrm{SD}) * *$ & $5.9 \pm 2.8$ & $7.9 \pm 2.8$ & $7.5 \pm 2.6$ & $F(2,388)=12.643$ & 0.001 \\
\hline
\end{tabular}

$* p<0.05 ; * *<0.001$. 
Table 3: Hockey, symptom and total knowledge index by previous concussion and group

\begin{tabular}{|c|c|c|c|c|}
\hline TBI history & Group $(n)$ & Knowledge score $(\operatorname{mean} \pm \mathrm{SD})$ & Symptom score $($ mean \pm SD) & Total knowledge index $($ mean \pm SD) \\
\hline \multirow[t]{3}{*}{ Yes } & Players (20) & $2.4 \pm 0.8$ & $4.4 \pm 2.4$ & $6.8 \pm 2.9$ \\
\hline & Coaches (37) & $2.5 \pm 1.1$ & $5.5 \pm 2.5$ & $8.0 \pm 2.7$ \\
\hline & Parents (83) & $2.1 \pm 0.9$ & $5.5 \pm 2.4$ & $7.6 \pm 2.6$ \\
\hline \multirow[t]{3}{*}{ No } & Players (51) & $1.8 \pm 1.0$ & $3.9 \pm 2.3$ & $5.7 \pm 2.7$ \\
\hline & Coaches (30) & $2.4 \pm 0.9$ & $5.4 \pm 2.5$ & $7.7 \pm 2.9$ \\
\hline & Parents (15) & $2.2+0.9$ & $5.4 \pm 2.3$ & $7.6 \pm 2.6$ \\
\hline
\end{tabular}

$\mathrm{TBI}=$ traumatic brain injury

significant $(F(2,388)=6.173, p=0.002)$. Mean concussion symptom knowledge scores were also low (players $4 / 10$, coaches 5.3/10, parents 5.5/10). Differences in mean symptom knowledge scores between players and coaches as well as between players and parents were statistically significant $(F(2,388)=10.167$, $p=0.001)$. Differences in symptom scores between coaches and parents were not significant. Finally, the total knowledge index by group was as follows: players 5.9/15, parents 7.5/15 and coaches $7.8 / 15$. Differences in total knowledge index between players and coaches and between players and parents were statistically significant $(F(2,388)=12.643, p=0.000)$.

\section{History of Concussion}

Table 3 reports concussion history by study group, mean knowledge scores, symptom sub-scores and total knowledge index. In all categories, mean sub-scores were higher among participants with a history of concussion, with the exception of knowledge scores for parents.

\section{Attitudes}

Table 4 displays the MTKSs for each response to the attitude questions. A significant statistical difference across study groups on all attitude questions emerged. When asked how serious they perceived a concussion, among players with the highest MTKS (7.0/13), 46.7\% selected the "more serious". Parents with the highest MTKS (7.8/13), 57.7\% also selected "more serious". Whereas, coaches with the highest MTKS (8/13) a total of $32.8 \%$ reported "as serious". Regarding likelihood of concussion, players with the highest MTKS (6.8/13), $25 \%$ claimed "likely". Among parents with the highest MTKS (7.8/13), 40.9\% selected "likely". However, coaches with the highest MTKS (8.2/13), at total of $49.3 \%$ selected "somewhat likely". Finally, when asked how worried are you or your child about getting a concussion this year, players with the highest MTKS (6.5/13), 8\% were "very worried". Coaches with the highest MTKS (8.5/13), 35.3\% worried "a little bit". Among parents with the highest MTKS (7.8/13) a total of $43.5 \%$ also worried "a little bit".

\section{Sources of Information About Concussion}

Players, coaches and parents identified multiple sources of information about concussion as illustrated in Figure 1. The greatest proportion of players identified parents/guardian $(58.7 \%)$, while most coaches identified coaches/managers/ officials $(54.4 \%)$. The majority of parents identified doctor/nurse (45.6\%). Players and coaches were significantly more likely than parents to report they had gained information from coach/

Table 4: Attitudes of participant groups with responses by mean total knowledge scores

\begin{tabular}{|c|c|c|c|c|c|c|c|}
\hline \multirow[t]{2}{*}{ Attitudes } & \multicolumn{2}{|c|}{ Players } & \multicolumn{2}{|c|}{ Coaches } & \multicolumn{2}{|c|}{ Parents } & \multirow[t]{2}{*}{$\chi^{2}$} \\
\hline & $n(\%)$ & Mean \pm SD & $n(\%)$ & Mean $\pm S D$ & $n(\%)$ & Mean $\pm S D$ & \\
\hline \multicolumn{8}{|l|}{ How serious? } \\
\hline a) Less serious & $3(4.3)$ & $5.7 \pm 2.3$ & $2(3.0)$ & $7.0 \pm 1.4$ & $1(.4)$ & $7.0 \pm 0$ & $10.421 *$ \\
\hline b) As serious as & $34(49.3)$ & $5.4 \pm 2.8$ & $22(32.8)$ & $8.1 \pm 2.7$ & $101(41.9)$ & $7.3 \pm 2.8$ & \\
\hline c) More serious & $32(46.4)$ & $7.0 \pm 2.8$ & $43(64.2)$ & $8.0 \pm 2.7$ & $139(57.7)$ & $7.8 \pm 2.5$ & \\
\hline \multicolumn{8}{|l|}{ How likely? } \\
\hline a) Likely & $18(25.0)$ & $6.8 \pm 3.3$ & $24(35.8)$ & $7.8 \pm 3.2$ & $101(40.9)$ & $7.8 \pm 2.8$ & $13.037 *$ \\
\hline b) Somewhat likely & $35(48.6)$ & $5.7 \pm 2.8$ & $33(49.3)$ & $8.2 \pm 2.4$ & $119(48.2)$ & $7.5 \pm 2.5$ & \\
\hline c) Unlikely & $19(26.4)$ & $5.2 \pm 2.2$ & $10(14.9)$ & $7.6 \pm 3.1$ & $27(10.9)$ & $7.0 \pm 2.8$ & \\
\hline \multicolumn{8}{|l|}{ How worried? } \\
\hline a) Not at all & $20(26.7)$ & $5.2 \pm 2.3$ & $6(8.8)$ & $7.7 \pm 3.1$ & $27(10.9)$ & $6.6 \pm 3.4$ & $24.507 *$ \\
\hline b) A little bit & $35(46.7)$ & $6.1 \pm 2.5$ & $24(35.3)$ & $8.5 \pm 2.2$ & $108(43.5)$ & $7.8 \pm 2.3$ & \\
\hline c) Quite a bit & $14(18.7)$ & $6.4 \pm 3.8$ & $25(36.8)$ & $7.5 \pm 3.1$ & $58(23.4)$ & $7.6 \pm 2.6$ & \\
\hline d) Very worried & $6(8.0)$ & $6.5 \pm 3.6$ & $13(19.1)$ & $7.7 \pm 3.1$ & $55(22.2)$ & $7.6 \pm 2.8$ & \\
\hline
\end{tabular}

$* p<0.05$ (maximum total knowledge score $=13$ ). 


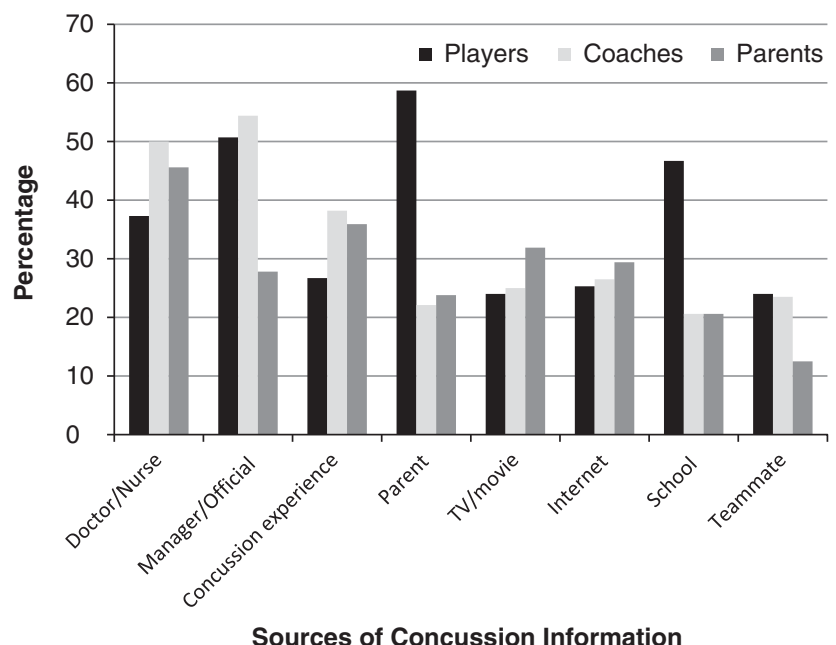

Figure 1: Sources of concussion information by players, coaches and parents.

manager/officials $\left(\chi^{2}=23.856, p=0.000\right)$. Players were significantly more likely than coaches and parents to gain information from parents $\left(\chi^{2}=35.817, p=0.000\right)$. Players were significantly more likely than coaches or parents to gain information from school/ teachers/work $\left(\chi^{2}=21.688, p=0.000\right)$. Players and coaches were significantly more likely than parents to acquire information from a teammate/friend $\left(\chi^{2}=8.326, p=0.016\right)$.

\section{DISCUSSION}

A convenience sample of First Nations people attending a 3-day youth hockey tournament completed a short survey about concussion. The proportion of correct responses were compared across three study groups, players $(n=75)$, parents $(n=248)$ and coaches $(n=68)$. The study is believed to be one of the first to investigate First Nations knowledge, attitudes and sources of information about concussion in collaboration with Indigenous peoples from Ontario.

\section{Knowledge and Attitudes}

Mean knowledge index scores by study group were coaches $7.9 / 15(52.6 \%)$, parents 7.5/15 (50\%) and players 5.9/15 (39.3\%). For players and coaches with a history of a concussion, knowledge scores were higher. This was also true for parents however, knowledge scores improved minimally for those with a history of concussion. Other research examining parental knowledge of concussion supports our findings of knowledge deficits even among parents who had experienced their own concussion. ${ }^{28,29}$ Players with the lowest knowledge scores demonstrated the most concerning attitudes, feeling concussion was "unlikely" and being "not at all worried" about a concussion while playing hockey. As the tournament took place at the end of the hockey season perhaps concussion knowledge that might have been provided earlier in the season was waning. However, other studies investigating nonIndigenous youth athletes reported low knowledge levels regarding symptoms and dangers of concussion even when pre-season education had occurred. ${ }^{32,33}$ Our findings support other Canadian reports from non-Indigenous populations, where youth reported misunderstandings of symptom duration and safety. ${ }^{16,24,34}$ These are important findings as misunderstandings and lack of knowledge can lead to dangerous health outcomes for youth playing hockey. Misconceptions about concussion by parents and coaches may lead to poor information being passed down to youth. Studies have shown younger players compared to older players demonstrated less perception of vulnerability while playing hockey. ${ }^{32}$ These findings further highlight the urgency of concussion education for First Nations players, coaches and parents. The influences and teachings of parents, family and elders are of upmost importance to learning for Indigenous youth and these community members will have to be consulted in the planning of any interventions. ${ }^{19}$

Studies among non-indigenous populations have identified approaches to prevention and education that may offer insights for Indigenous communities. For example, the use of protective equipment in hockey including helmets, mouthguards and neckguards $^{1,34}$ is not always available for Indigenous youth. Programs to provide proper hockey equipment to Indigenous youth are immediately needed. Pre-season physical activity and training including conditioning of the neck muscles may also be helpful to prevent a concussion. ${ }^{9,12}$ Education provided to players, parents and coaches can be augmented through web-based education and videos such as Parachute ${ }^{36}$ and the CATT program from British Columbia. $^{35}$ Others advocate for "concussion road shows", ${ }^{12}$ which would be well suited for the large LNHL hockey tournament. Bringing concussion education through invited speakers such as nurses, physicians, media and hockey personalities to a wide tournament audience could benefit attendees. Pre-season hockey team meetings and locker room posters urging players to report concussion are other supportive educational strategies. ${ }^{12}$ Improving coach approachability and communication of coaches with youth could also be helpful. ${ }^{39}$ Fair play rules and enforcement to reduce and eliminate body checking can also be promoted. ${ }^{34}$ Fair play rules can also reward teams for not committing fouls in hockey. ${ }^{34}$ Finally, sport-specific and hockey player position-specific strategies may also play an important role in concussion awareness and prevention. ${ }^{9}$ However, it is worth noting that many of these strategies require further evaluation to validate their preventative effectiveness.

\section{Call for Cultural Safety in Concussion Knowledge Translation for Indigenous Populations}

Cultural factors can also play an important role in the uptake and maintenance of injury prevention strategies. ${ }^{9,17,19}$ A growing body of evidence has described the importance of education programs for reducing injury rates in youth hockey. ${ }^{34}$ Study participants reported receiving information about concussion from a wide variety of sources. Our findings suggest that both sportsbased and school-based programs could effectively reach a wide Indigenous audience. However, the educational training that the individuals presenting these programs may have received is not well known. Only recently in Canada have programs targeted to parents and coaches been more clearly defined in their content and been readily available. ${ }^{35,36}$

Other educational programs continue to be developed and implemented with no record or requirements for safety content. ${ }^{37}$ In our study half of all participants reported receiving concussion information from a nurse or doctor. Even among health care professionals standardized knowledge translation for concussion has not been established. ${ }^{8,38}$ The Canadian federal government in collaboration with the Public Health Agency of Canada, 
Parachute Canada and the National Sport Organizations have recently released the Canadian Guideline for Concussion in Sport that include pre-season education for all stakeholders. This could be a valuable resource that may need to be adapted for First Nations populations.

Many Indigenous youth have not benefitted to the same degree as other Canadian youth from safety campaigns such as car seats, seat belts, swimming lessons and first aid training. ${ }^{39,40}$ The lack of culturally appropriate and targeted prevention programs for Indigenous youth is a barrier to knowledge and to the ability to reduce injury rates through education. ${ }^{17}$ Concussion education strategies should be adapted to the local context. ${ }^{9}$ Community is known to be extremely important and connected to health and wellness in the Indigenous population. ${ }^{41}$ Concussion awareness interventions should be culturally guided and focused on collaboration with community organizations. ${ }^{18}$ Collaboration with elders and respected community members such as coaches can help. A cultural safety approach to education and prevention is needed to fit the target groups of players, parents and coaches within the Indigenous world views and social, economic and political context in determining actionable strategies to support the reduction of injuries. ${ }^{42,43}$ Culturally safe health strategies for Indigenous youth can help them to share their perspective on pain. ${ }^{44}$

\section{Study Limitations}

This study had several limitations. Study participants were a convenience sample not a random group. Individuals self-selected into the survey group and their decisions to complete may have been influenced by their concussion awareness. As no definition of a concussion was provided, participants may not have met standard definitions for having previously sustained a concussion. Despite asking subjects to be truthful in their responses, the excitement of the hockey tournament and presence of peers and parents may have influenced responses toward those that were socially desirable. Concussion history relied on self-reports and may not represent what might have happened in "real-life situations". ${ }^{33}$ In addition responses may have also been susceptible to recall bias. ${ }^{45}$ The First Nations tournament does not allow body checking so participants reporting previous concussions may be a result of other sports, activities or events. The survey instrument by Mzaik et al. ${ }^{32}$ was not developed for adults. The modifications undertaken for this study may have impacted instrument validity.

Future studies should investigate whether higher levels of concussion knowledge and higher attitudes toward the severity of concussion influence behavior on the ice, the number of concussions experienced and symptom reporting. ${ }^{37}$ Further examination of First Nations players, parents and coaches attitudes toward concussion may also be helpful to improve understanding and to inform future concussion awareness and prevention strategies. Examining the quality of concussion health care available to First Nations communities also warrants further study.

\section{CONCLUSIONS}

This study raises concern about concussion knowledge, symptom awareness and attitudes about concussion among First Nations youth who play hockey, as well as their coaches and parents. Encouraging First Nations youth to participate in hockey must be accompanied by activities to educate about and to prevent concussion. Immediate attention is required to adopt an Indigenous lens to build culturally safe approaches to any intervention.

\section{ACKNOWLEDGMENTS}

The authors thank Rishothan Yogananthan, Raiyan Chowdhury and Rachel Chin for their contribution to this project. The authors also thank the First Nations study participants who completed the survey.

\section{Disclosure}

$\mathrm{CH}, \mathrm{AM}, \mathrm{CL}, \mathrm{LM}, \mathrm{TJ}$ and $\mathrm{DO}$ do not have anything to disclose.

\section{REFERENCES}

1. Benson BW, Hamilton GM, Meeuwisse WH, McCrory P, Dvorak J. Is protective equipment useful in preventing concussion? A systematic review of the literature. Br J Sports Med. 2009; 43(Suppl 1):i56-i67.

2. Sim A, Terryberry-Spohr L, Wilson KR. Prolonged recovery of memory functioning after mild traumatic brain injury in adolescent athletes. J Neurosurg. 2008;108(3):511-6.

3. Cusimano MD, Taback NA, McFaull SR, Hodgins R, Bekele TM, Elfeki N. Effect of body checking on rate of injuries among minor hockey players. Open Med. 2011;5(1):E57.

4. Laurer HL, Bareyre FM, Lee VM, et al. Mild head injury increasing the brain's vulnerability to a second concussive impact. J Neurosurg. 2001;95(5):859-70.

5. McCrory P, Davis G, Makdissi M. Second impact syndrome or cerebral swelling after sporting head injury. Curr Sports Med Rep. 2012;11(1):21-3.

6. Babcock L, Byczkowski T, Wade SL, Ho M, Mookerjee S, Bazarian JJ. Predicting post-concussion syndrome after mild traumatic brain injury. JAMA Pediatr. 2013;167(2):156-61.

7. Eisenberg MA, Meehan WP, Mannix R. Duration and course of post concussive symptoms. Pediatrics. 2014;133(6):999-1006.

8. Ellis MJ, Ritchie LJ, McDonald PJ, et al. Multidisciplinary management of pediatric sports-related concussion. Can J Neurol Sci. 2017;44:24-34.

9. Emery CA, Black AM, Kolstad A, et al. What strategies can be used to effectively reduce the risk of concussion in sport? Br J Sports Med. 2017;51(12):978-84

10. Nolin P, Villemure R, Heroux L. Determining long-term symptoms following mild traumatic brain injury: method of interview affects self-report. Brain Injury. 2006;20(11):1147-54.

11. Hiploylee C, Dufort PA, Davis HS, et al. Longitudinal study of postconcussion syndrome: not everyone recovers. J Neurotrama. 2017;34(8):1511-23

12. Tator $\mathrm{CH}$. Concussions and their consequences: current diagnosis, management and prevention. CMAJ. 2013;185(11):975-9.

13. Williams MW, Rapport LJ, Millis SR, Hanks RA. Psychosocial outcomes after traumatic brain injury: life satisfaction, community integration, and distress. Rehabil Psychol. 2014;59(3):298.

14. Bryant RA, O'donnell ML, Creamer M, McFarlane AC, Clark CR, Silove D. The psychiatric sequelae of traumatic injury. Am J Psychiatry. 2010;167(3):312-20.

15. Lukow HR, Godwin EE, Marwitz JH, Mills A, Hsu NH, Kreutzer JS. Relationship between resilience, adjustment, and psychological functioning after traumatic brain injury: a preliminary report. J Head Trauma Rehabil. 2015;30(4):241-8.

16. Cusimano MD, Topolovec-Vranic J, Zhang S, Mullen SJ, Wong M, Ilie G. Factors influencing the underreporting of concussion in sports: a qualitative study of minor hockey participants. Clin J Sport Med. 2017;27(4):375-80.

17. Banerji A. Preventing unintentional injuries in Indigenous children and youth in Canada. Pediatr Child Health. 2012;17(7):393.

18. Zeiler KJ, Zeiler FA. Social determinants of traumatic brain injury in the North American Indigenous population: a Review. Can J Neurol Sci. 2017;44(5):525-31.

19. Ross A, Dion J, Cantinotti M, Collin-Vézina D, Paquette L. Impact of residential schooling and of child abuse on substance use problem in Indigenous Peoples. Addict Behav. 2015;51:184-92. 
20. Blackmer J, Marshall SC. A comparison of traumatic brain injury in the Saskatchewan native North American and non-native North American populations. Brain Injury. 1999;13(8):627-35.

21. Dudley RW, Feyz M, Maleki M, Marcoux J. Comparison of traumatic brain injury (TBI) between Aboriginal communities of Northern Quebec and the general Quebec population. Can J Neurol Sci. 2012;39(Suppl 3):S20.

22. Manley G, Gardner AJ, Schneider KJ, et al. A systematic review of potential long-term effects of sport-related concussion. Br J Sports Med. 2017;51(12):969-77.

23. Hunt C, Zanetti K, Kirkham B, et al. Identification of hidden health utilization services and costs in adults awaiting tertiary care following mild traumatic brain injury in Toronto, Ontario, Canada. Concussion. 2016;1(4).

24. McCrory P, Meeuwisse W, Dvorak J, et al. Consensus statement on concussion in sport-the $5^{\text {th }}$ International Conference on Concussion in Sport held in Berlin, October 2016. Br J Sports Med. 2017;51(21):1557-58.

25. McCrory P, Meeuwisse WH, Aubry M, et al. Consensus statement on concussion in sport: the 4th International Conference on Concussion in Sport held in Zurich, November 2012. Br J Sports Med. 2013;47:250-8.

26. Marar M, McIlvain NM, Fields SK, Comstock RD. Epidemiology of concussions among United States high school athletes in 20 sports. Am J Sports Med. 2012;40(4):747-55.

27. Register-Mihalik JK, Guskiewicz KM, McLeod TCV, Linnan LA, Mueller FO, Marshall SW. Knowledge, attitude, and concussionreporting behaviors among high school athletes: a preliminary study. J Athl Train. 2013;48(5):645-53.

28. Lin AC, Salzman GA, Bachman SL, et al. Assessment of parental knowledge and attitudes toward pediatric sports-related concussions. Sports Health. 2015;7(2):124-9.

29. Stevens PK, Penprase B, Kepros JP, Dunneback J. Parental recognition of postconcussive symptoms in children. J Trauma Nurs. 2010;17(4):178-82.

30. Guilmette TJ, Malia LA, McQuiggan MD. Concussion understanding and management among New England high school football coaches. Brain Injury. 2007;21(10):1039-47.

31. National Steering Committee of the First Nations and Inuit Regional Longitudinal Health Survey. First Nations Principles of Ownership, Control, Access and Possession (OCAP). 2015. Retrieved from www.FNIGC.ca/OCAP. Accessed June 20, 2017.

32. Mrazik M, Perra A, Brooks BL, Naidu D. Exploring minor hockey players' knowledge and attitudes toward concussion: implications for prevention. J Head Trauma Rehabil. 2015;30(3):219-27.

33. Anderson BL, Gittelman MA, Mann JK, Cyriac RL, Pomerantz WJ. High school football players' knowledge and attitudes about concussions. Clin J Sport Med. 2015;26(3):206-209.

34. Cusimano MD, Nastis S, Zuccaro L. Effectiveness of interventions to reduce aggression and injuries among ice hockey players: a systematic review. CMAJ. 2013;185(1):57-69.

35. BC Research and Injury Prevention. Concussion awareness training toolkit. Retrieved from http://www.injuryresearch.bc.ca/education/ concussion-awareness-training-tool/. Accessed June 18, 2017.

36. Parachute Canada. Canadian guideline on concussion in sport. Retrieved from http://www.parachutecanada.org/injury-topics/ topic/C9. Accessed June 15, 2015.
37. Eagles ME, Bradbury-Squires DJ, Powell MF, Murphy JR, Campbell GD, Maroun FB. The impact of a concussion-U educational program on knowledge of and attitudes about concussion. Can J Neurol Sci. 2016;43(5):659-64.

38. Burke MJ, Chundamala J, Tator $\mathrm{CH}$. Deficiencies in concussion education in Canadian medical schools. Can J Neurol Sci. 2012; 39(6):763-6.

39. Kroshus E, Garnett B, Hawrilenko M, Baugh CM, Calzo JP. Concussion under-reporting and pressure from coaches, teammates, fans, and parents. Soc Sci Med. 2015;134:66-75.

40. Harrop AR, Brant RF, Ghalo WA, Macarthur C. Injury mortality rates in native and on-native children: a population study. Public Health Rep. 2007;122(3):339-46.

41. King M, Smith A, Gracey M. Indigenous health part 2: the underlying causes of the health gap. Lancet. 2009;374:76-85.

42. Giles AR, Hognestad S, Brooks LA. The need for cultural safety in injury prevention. Public Health Nurs. 2015;32(5):543-9.

43. Smylie J, Kaplan-Myrth N, McShane K., Metis Nation of Ontario Ottawa Council, Pikwakanagan First Nation, and Tungasuvvingat Inuit Family Resource Centre. Indigenous knowledge translation: baseline findings in a qualitative study of pathways of health knowledge in three Indigenous communities in Canada. Health Promot Pract. 2009;10:436-46.

44. Latimer M, Finley A, Rudderham S, et al. Expression of pain among Mi'Kmaq children in one Atlantic Canadian community; a qualitative study. Can Med Assoc. 2014;2(3): E133-8.

45. Iverson GL, Lange RT, Brooks BL, Rennison VLA. "Good old days" bias following mild traumatic brain injury. Clin Neuropsychol. 2010;24:17-37.

\section{APPENDIX}

How long do you think symptoms of concussion can last?
a) 10 days
b) 10 months
c) 2 years
d) 5 years

When do you think a child or teen can go back to school after a concussion?

a) Next day

b) Half days

c) Every brain heals differently so you will need to discuss with the health care provider

d) A week

Have you ever suffered a concussion or blow to the head or body that caused you to be dazed or confused?

Yes, If yes, how many times has this happened to you

No, I have never suffered a concussion 